\section{Amount vs contrast of masking-figure contour in visual backward masking***}

\author{
WILLIAM N. DEMBER, THOMAS L. COLINA $\dagger$ \\ and MICHAEL F. SHERRICK †† \\ University of Cincinnati, Cincinnati, Ohio 45221
}

In an earlier study on configurational factors in visual backward masking, varying amounts were deleted from the contour of a masking ring, and it was found that mask effectiveness was directly related to amount of contour present in the masking figure. In response to a question about whether the independent variable in that study was correctly identified as amount of contour in the masking figure rather than perhaps as the amount of its average contrast, we compared the masking effectiveness of both variables in the present experiment. The target was a black disk; its detectability was assessed by a two-alternative spatial forced-choice indicator response. The data clearly support the identification of the independent variable in the earlier study as amount of ring contour, although the two variables do have qualitatively similar effects on masking.

As part of a larger project on configurational factors in visual backward masking, Sherrick \& Dember (1970) investigated the variables of amount and distribution of the masking figure's contour. The basic masking figure in that study was a black ring, and the target stimulus was a black disk. In order to accommodate a spatial forced-choice detection task, the masking field actually contained two identical rings, side by side; the target disk was presented randomly within one or the other ring, and the S's task was to indicate target location.

Amount of mask contour was manipulated by deleting $0 \%, 20 \%$, $40 \%, 60 \%, 80 \%$, or $100 \%$ of the basic ring figure. "Distribution" was manipulated by deleting the appropriate amount of contour either in one continuous segment or in four equally spaced segments. The results of the Sherrick and Dember experiment showed both variables to be significant: (1) the greater the amount of mask-figure contour present, the greater the amount of masking; (2) more masking occurred when the remaining contour was symmetrically distributed.

The present study follows up the first of the above two findings. When the Sherrick and Dember experiment was reported at the Midwestern Psychological Association meetings in 1968 , a question was raised from the

* This research was supported by Grant EY 00481-05 from the National Eye Institute.

* *Requests for reprints should be sent to William N. Dember, Department of Psychology. University of Cincinnati, Cincinnati, Ohio 45221 .

+ Now at the University of Western Ontario, London, Ont., Canada

+ Now at the Memorial University of New foundland, St. John's, Newfoundland, Canada. floor to which we then had no answer: Was what we thought of as a manipulation of "amount of mask contour" really that or were we simply manipulating the average contrast level of the masking figure? That is, would the effect on masking be the same if, instead of deleting a given portion of the ring contour, we decreased its contrast by a proportionate amount, while retaining a complete ring?

It was our expectation that the two manipulations-deletion of contour and contrast reduction-would not have quantitatively equivalent effects, as suggested by the importance of the "distribution" variable in the Sherrick and Dember experiment. Nevertheless, a direct answer to the question would be desirable, and the present experiment was designed to that end. PROCEDURE

The Ss were four male and four female college students with normal vision. Prior to the experiment proper, each $\mathrm{S}$ received a total of 800 training trials. black disk drawn in ink on a white index card. Each masking stimulus consisted of a pair of identical rings. The partial rings were drawn in black ink on white index cards and contained $75 \%, 50 \%$, or $25 \%$ of the total contour, symmetrically distributed in four equal segments. The continuous gray rings were cut from Munsell paper and pasted onto white index cards. Each pair of continuous rings was cut from a different shade of gray paper, chosen to reflect $25 \%, 50 \%$, or $75 \%$ of the light reflected by the white background cards, as measured by a Spectra brightness meter.

The diameter of the disk and the inner diameter of the rings subtended $26 \mathrm{~min}$ of visual arc. The outer
The target stimulus was a solid diameter of the rings was $54 \mathrm{~min}$, and the width of the ring contour was $14 \mathrm{~min}$ of are. A distance of $66 \mathrm{~min}$ of arc separated the centers of the two rings.

The order of presentation of the eight experimental conditions (black rings, no rings, three partial contours, three shades of gray) was randomized independently for each $S$. Disk location was random, and the $\mathbf{S}$ responded by saying "left" or "right" after each trial. In each testing condition, Ss viewed each of the eight conditions once in blocks of 25 trials. Four testing sessions, one per day, yielded a total of 100 trials for each condition for each $\mathbf{S}$.

The stimuli were presented tachistoscopically (Scientific Prototype Model GX). A trial consisted of the following sequence: fixation field, target field, mask field, fixation field. Target and mask durations were 15 and $100 \mathrm{msec}$ respectively. The termination of the target defined the onset of the mask $($ ISI $=0)$. The fixation field remained on between trials. The luminance of each field was $25 \mathrm{fL}$. Viewing was monocular.

\section{RESULTS AND DISCUSSION}

The results are shown graphically in Fig. 1. A repeated-measures analysis of variance verified the significance of the two main effects apparent in the figure: (1) extent of masking increased with increasing integrity (completeness or contrast) of masking-ring contour $(\mathrm{p}<.001)$, and $(2)$ deletion and contrast reduction are not quantitatively equivalent $(p<.001)$ At a given level of integrity, a broken mask is more effective than a gray mask. The interaction between amount and source of "disintegrity" was not significant $(p<.10)$. Note that the above conclusions are based on an analysis that excluded both the complete black rings and the no-rings condition; at those data points, the sources of disintegrity are inseparable.

For the sake of interexperiment comparison, data from the "distributed" condition of the Sherrick \& Dember (1970) study are included in Fig. 1. Considering the several possible sources of difference between the two experiments (e.g. different $S s$ and Es, different combinations of conditions employed, different values of ring incompleteness), the similarity between the two sets of data is quite impressive.

As indicated above, the present results clearly answer the question posed by the Sherrick and Dember experiment: Deleting ring segments and reducing ring contrast are not quantitatively equivalent, although they do have similar impact on mask 


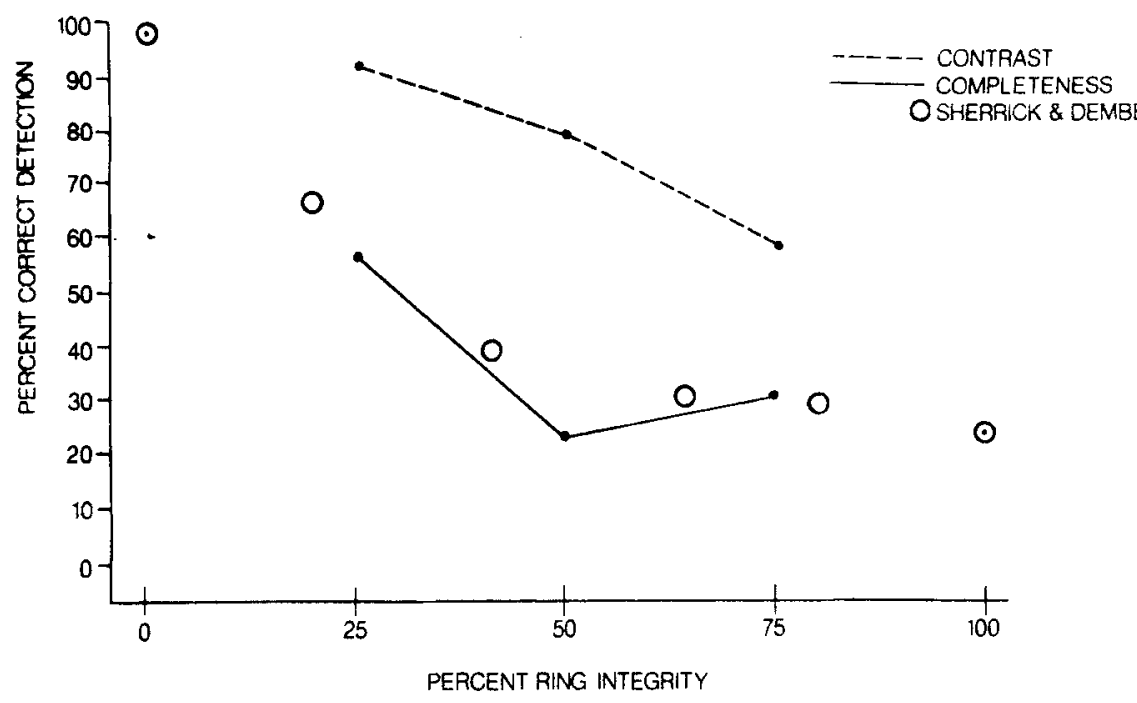

Fig. 1. Mean percentage correct detection, corrected for chance guessing, plotted as a function of percentage ring integrity (completeness or contrast). Open circles are data points from the condition in Sherrick \& Dember (1970) corresponding to the one labeled completeness in the present study.

effectiveness. An incomplete ring with a given percentage of its original contour present is a more effective mask than a complete ring with that percentage of its original contrast. This result is consistent with earlier findings (e.g., Werner, 1935; Sherrick \& Dember, 1968; Sherrick \& Dember, 1970 ) on the importance of contour in the masking field. The exact mechanism through which contour deleted and the remaining contour is distributed symmetrically around the disk-shaped target, then the greater the number of mask segments employed, the more effective the mask. In that experiment, number of mask segments varied from two to eight. If the number of segments were made large enough, the masking figure ought to appear like a hom ogeneous gray ring. But we know from the present data that such a figure would be a less effective mask than one comprised of discrete segments. Thus, at some point, there should be a reversal of the relation between number of ring segments and masking effectiveness reported by Sherrick \& Dember (1968).

\section{REFERENCES}

HUBEL, D. H., \& WEISEL, T. N. Receptive fields, binocular interaction and functional architecture in the cat's visual cortex. Journal of Physiology, 1962, 160 , 106-154.

SHERRICK, M. F., \& DEMBER, W. N. Configurational "factors in visual backward masking. Proceedings of the 76th Annual Convention of the American Psychological Association, 1968, 3, 111-112.

SHERRICK, M. F., \& DEMBER, W. N. Completeness and spatial distribution of mask contours as factors in visual back ward masking. Journal of $\begin{array}{llr}\text { back w ard } & \text { masking. Journal of } \\ \text { Experimental } & \text { Psychology, 1970, 84, }\end{array}$ 179-180.

WERNER, H. Studies on contour: I. Qualitative analysis. American Journal of Psychology, 1935, 47, 40-64. 